\title{
Zafirlukast in Combination with Pseudohypericin Attenuates Spinal Cord Injury and Motor Function in Experimental Mice [Corrigendum]
}

Chen XG, Hua F, Wang SG, Xu YY, Yue HT, Sun J. Drug

Des Devel Ther. 2018;12:2389-2402

The authors have advised Figures 1 (on page 2393),

Figure 3 (on page 2394), Figure 5 (on page 2395),
Figure 7 and Figure 8 (on page 2396) are incorrect due to a fault in their microscope camera. The correct Figures are shown below:
A

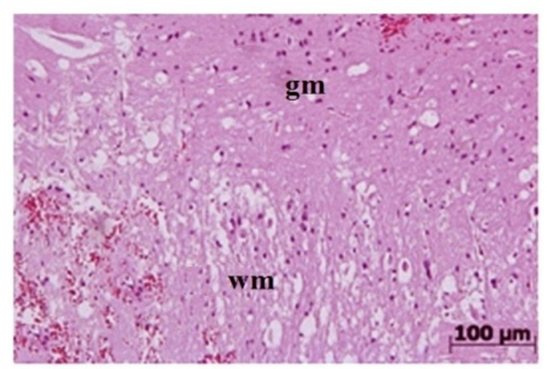

B

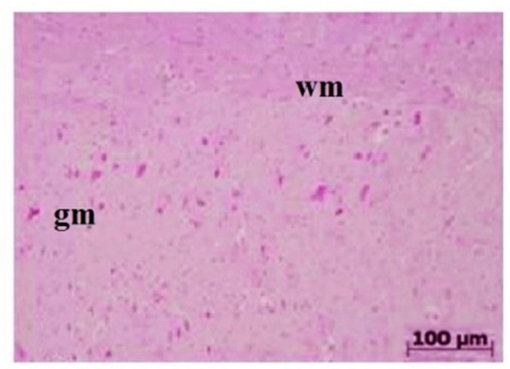

D

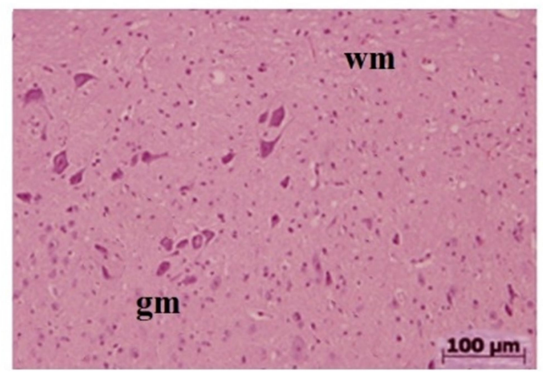

$100 \mu \mathrm{m}_{1}$

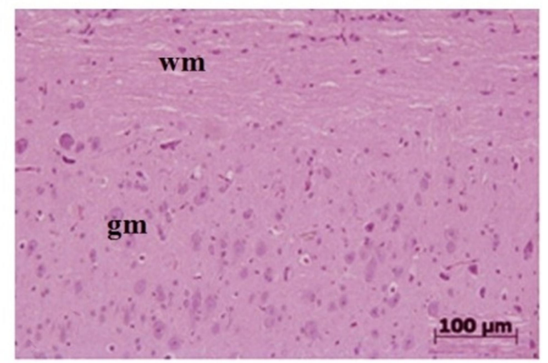

E

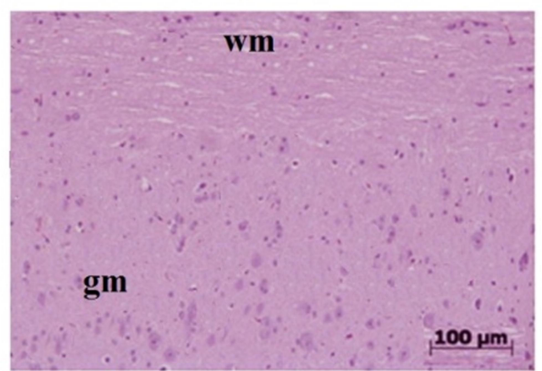

Figure I Effect of PHP and ZFL on histological changes on the spinal cord tissue after $24 \mathrm{~h}$ inducing spinal injury.

Notes: (A) Vehicle-treated control group showing occurrence of edema and changes in white matter of perilesional zone. (B) Sham-vehicle treated group mice showing no signs of changes. The severity of spinal cord injury decreased in tissues with reduction in edema and preservation of white matter observed in sections (C) PHP and (D) ZFL treated mice. The results were improved in (E) after combining PHP and ZFL. The produced figures are representatives of 3 experiments.

Abbreviations: PHP, pseudohypericin; ZFL, zafirlukast; wm, white matter, gm, grey matter. 
A

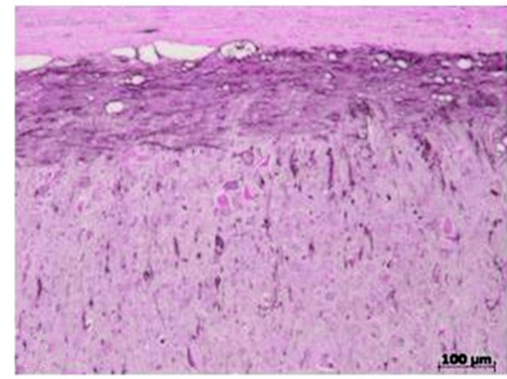

D

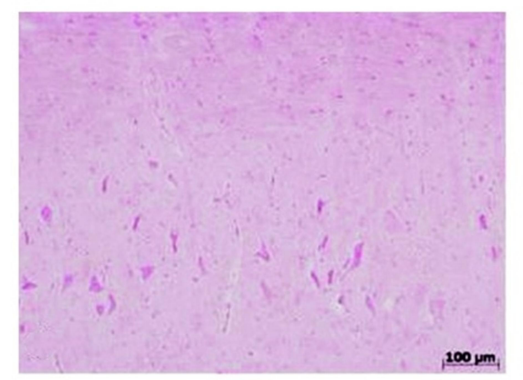

B

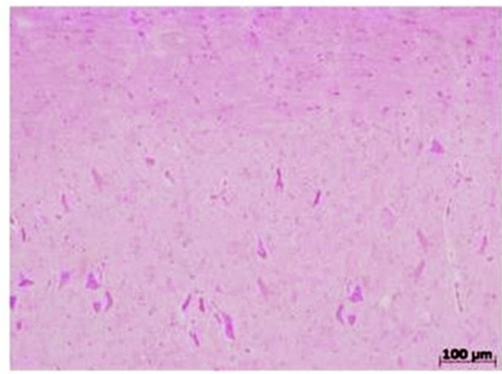

E

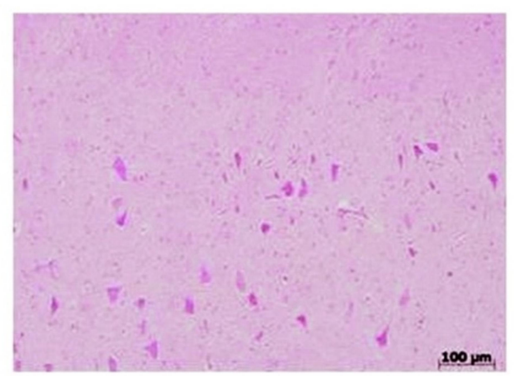

C

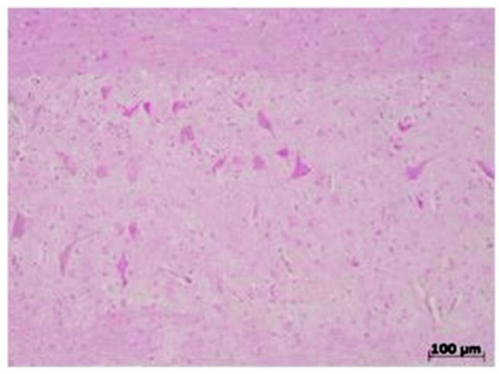

F

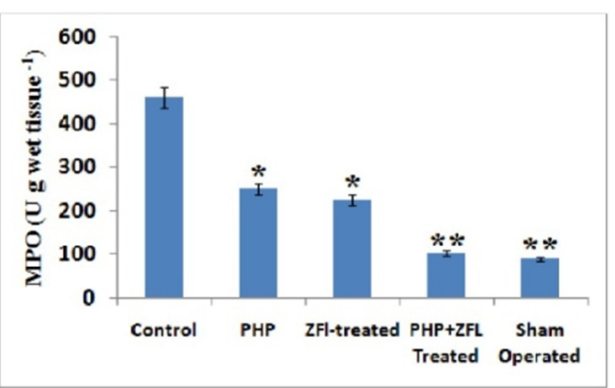

Figure 3 Immunohistochemical localization and activity of MPO in spinal tissue of mice treated with PHP and ZFL their combination.

Notes: In vehicle-treated control group mice, the tissue were stained positive for MPO and presented increased MPO activity (A and F). Sham-operated group mice, tissue sections showed no positive staining for MPO and also had normalized MPO activity (B and F). MPO staining in tissues sections from PHP (C), ZFL (D) and their combination (E) a significant reduction in positive staining for MPO activity was seen compared to vehicle treated control group. The produced figures are representatives of 3 experiments. Data are mean $\pm \% R S D(n=10), * P<0.001$ compared to control vehicle treated mice.

Abbreviations: MPO, myeloperoxidase; PHP, pseudohypericin; ZFL, zafirlukast; relative standard deviation.

A

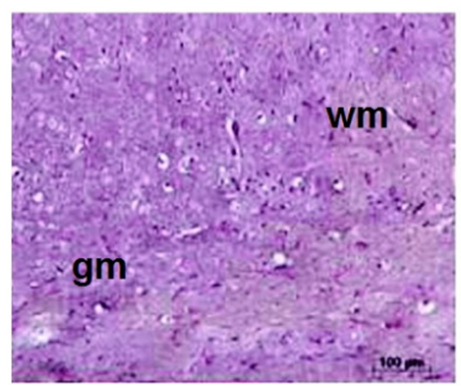

D

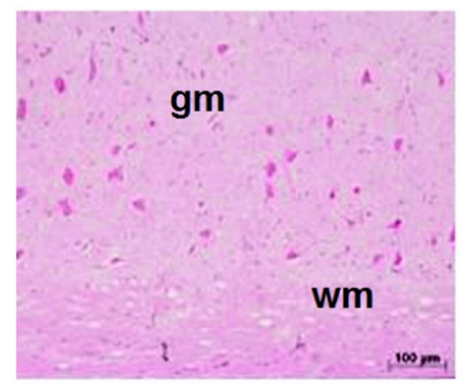

B

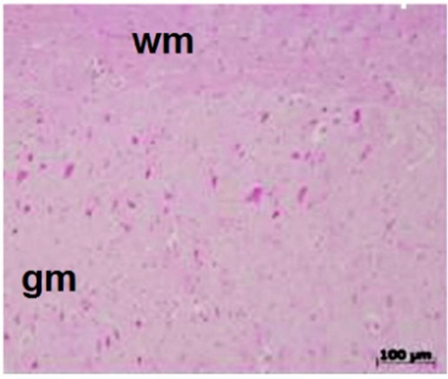

E

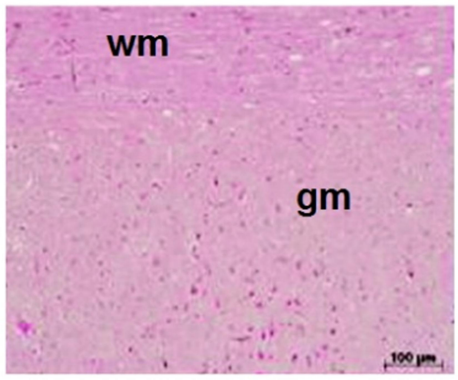

C

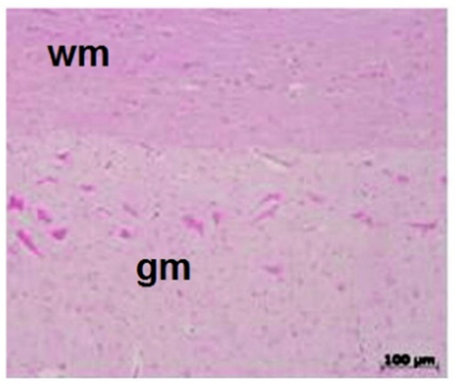

$\mathbf{F}$

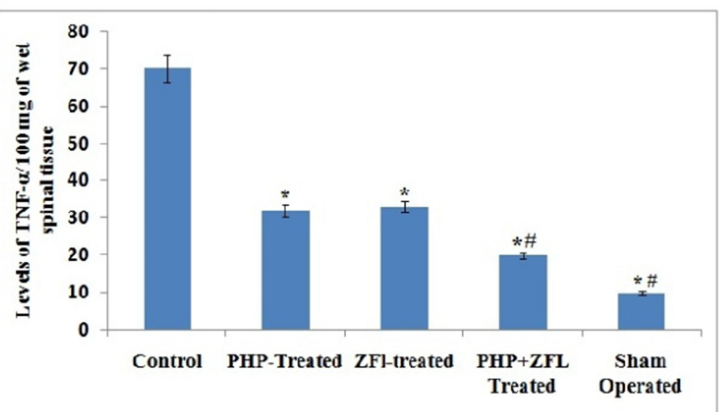

Figure 5 Effect of PHP and ZFL on tissue levels and immunohistochemical localization of TNF- $\alpha$.

Notes: The control vehicle treated group showed increased levels of TNF- $\alpha(\mathbf{F})$ and positive staining in spinal tissues (A). (B) Sham-group do not exhibited staining. The treatment of PHP, ZFL and their combination significantly $(* P<0.0 \mathrm{I})$ reduced levels of TNF- $\alpha$ compared to control $(\mathbf{F})$, also reduced the positive staining in spinal tissues $(\mathbf{C}$, $\mathbf{D}$ and $\mathbf{E}$ respectively). The results were highly significant $\left({ }^{\#} P<0.00 \mathrm{I}\right)$ in mice treated with combination and sham group compared to control.

Abbreviations: PHP, pseudohypericin; ZFL, zafirlukast; TNF- $\alpha$, tumor necrosis factor- $\alpha$; wm, white matter, gm, grey matter. 
A

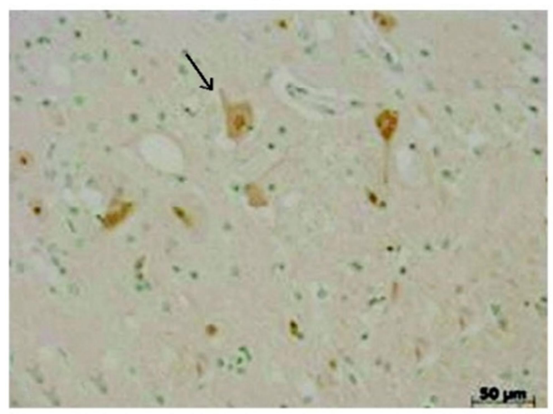

B

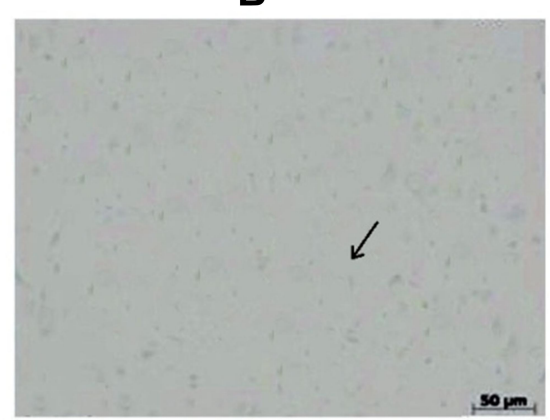

C

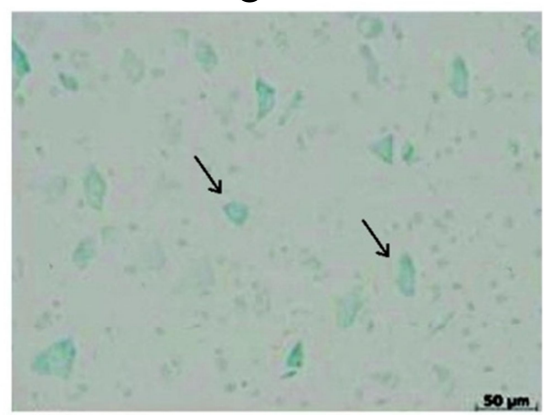

D

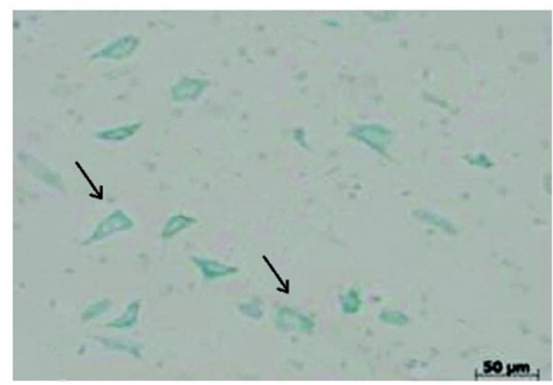

$\mathbf{E}$

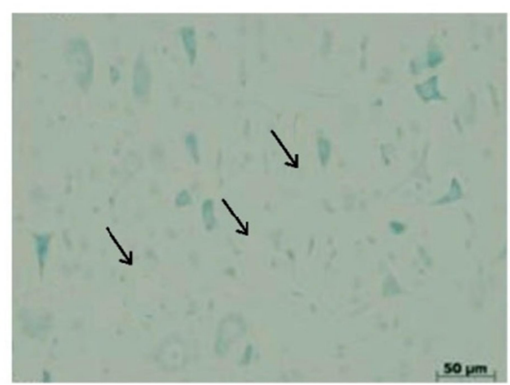

Figure 7 TUNEL assay of spinal cord tissue of mice subjected to spinal injury followed by treatment of PHP, ZFL and their combination.

Notes: The tissue harvested after $24 \mathrm{~h}$ of injury and received treatment of vehicle only showed appearance of brown color cells suggesting apoptosis (A). In contrast the tissues of mice treated with PHP (C), ZFL (D) and their combination (E) demonstrated reduction in number of apoptotic cells, no apoptotic fragments were detected in sham-operated vehicle treated mice spinal tissues (B). TUNEL- terminal deoxynucleotidyltransferase-mediated UTP end labelling assay. The arrows indicate the TUNEL positive cells.

Abbreviations: PHP, pseudohypericin; ZFL, zafirlukast; TUNEL, terminal deoxynucleotidyltransferase-mediated UTP end labeling.

A

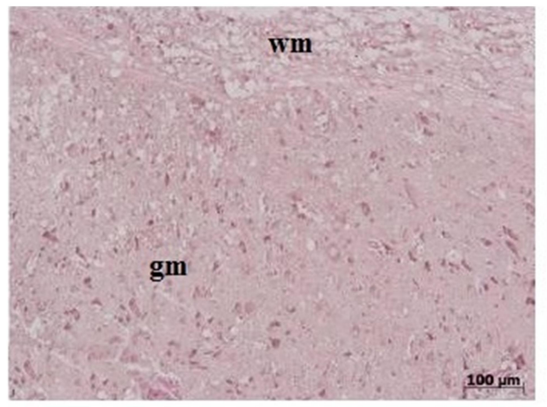

B

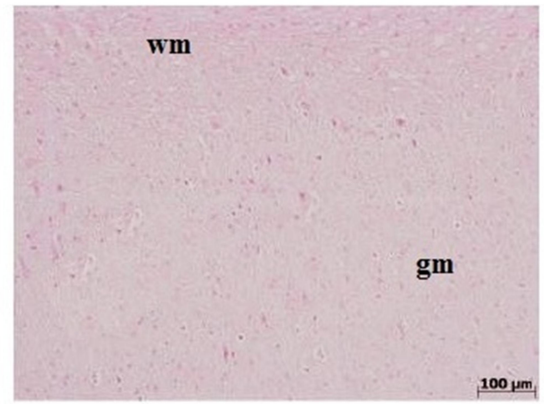

D

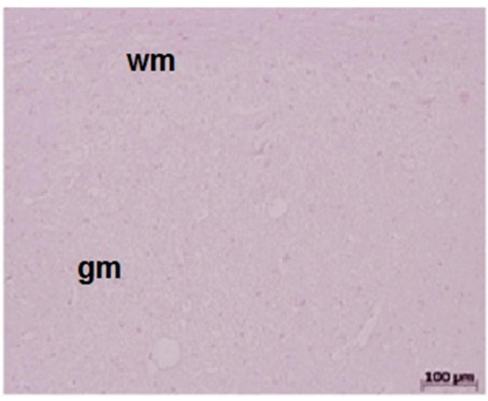

C

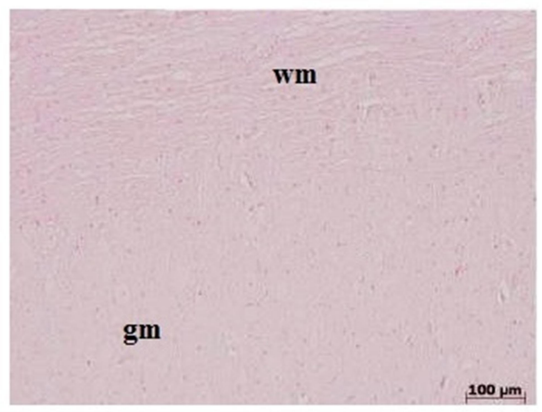

E

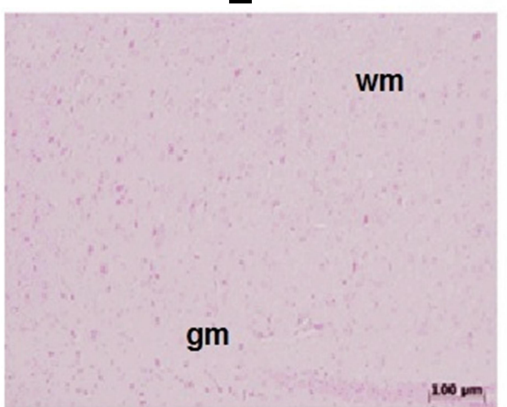

Figure 8 Results of immunohistological staining for FAS-L.

Notes: The spinal tissues sections obtained after $24 \mathrm{~h}$ of spinal injury showed positive staining for FAS-Ligand (A). The spinal tissue sections of mice after receiving treatment of PHP (C) and ZFL (D) showed decrease in number of cells positive for FAS-L. The positive stained FAS-L cells reduced more significantly in spinal tissues of mice receiving combined treatment of PHP and ZFL (E). The sham-operated mice tissues showed no staining for FAS-L (B).

Abbreviations: PHP, pseudohypericin; ZFL, zafirlukast; FAS-L, FAS ligand; wm, white matter; gm, gray matter. 


\section{Publish your work in this journal}

Drug Design, Development and Therapy is an international, peerreviewed open-access journal that spans the spectrum of drug design and development through to clinical applications. Clinical outcomes, patient safety, and programs for the development and effective, safe, and sustained use of medicines are a feature of the journal, which has also been accepted for indexing on PubMed Central. The manuscript management system is completely online and includes a very quick and fair peer-review system, which is all easy to use. Visit http://www. dovepress.com/testimonials.php to read real quotes from published authors. 